\title{
The Effect of Automatization of the Phonological Component on the Reading Comprehension of ESP Students
}

\author{
Mohammad Khatib \\ Allameh Tabataba'i University, Tehran, Iran \\ E-mail: mkhatib27@yahoo.com
}

Jalil Fat'hi (Corresponding Author)

Allameh Tabataba'i University, Tehran, Iran

Tel: 98-918-877-7239 E-mail: jfathi13@yahoo.com

Received: March 24, 2011

Accepted: April 15, $2011 \quad$ Published: November 1, 2011

doi:10.5539/ies.v4n4p192

URL: http://dx.doi.org/10.5539/ies.v4n4p192

\begin{abstract}
Prompted by the recent shift of attention from just focusing on the top-down processing in L2 reading towards considering the basic component, bottom-up processing, the role of phonological component has also enjoyed popularity among a selected circle of SLA investigators (Koda, 2005). This study investigated the effect of the automatization of the phonological component on the reading comprehension of the ESP students. After administering a reading section of a TOEFL test, sixty participants out of one hundred and thirty were selected from among ESP students volunteering to participate in this study. These sixty participants were randomly assigned to two groups namely, control group and experimental group. The result of the pre-test revealed that there was not any significance difference between the two groups prior to the treatment. Then, in the period of one semester, the control group received reading instruction through the automatization of phonological component (i.e. pronunciation practice) and the control group received the reading instruction based on the traditional approach which was based on literal translation of English words and sentences into their Persian equivalents. After the treatment, all the participants took the post-test. The result of an Independent-samples T-test indicated that teaching reading through the automatization of phonological component was more effective than the traditional approach in reading instruction. The result of this study is considered to be useful in methodological issues related to reading instruction and also teacher education programs. Moreover, the findings of this study have theoretical implications for SLA researchers.
\end{abstract}

Keywords: Automatization, Phonological component, ESP students, Top-down processing, Bottom-up processing

\section{Introduction}

The reading process has been studied and continues to be studied through the eyes of diverse schools of thought. Information processing approach has been an active contributor for the past 20 years with computers playing a strong role since 1980. Although information processing theorists have contributed to the understanding of reading, there remains a great amount of investigation for understanding the reading comprehension process: and an even greater need for understanding second language reading (Koda, 2005).

Since 1970 s, the focus of most of the studies have been on investigation of top-down processing, while little attention has been paid to lower-level processing; e.g., phonological processing. Recently, upon the emergence of Interactive Approaches to SL reading, and the unavoidable contribution of bottom-up components, the pendulum of L2 reading research has swung back towards the investigation of lower-level, component processing (Koda, 2005).

Reading, as one of the most attention-grabbing language skills, is a complex cognitive skill which uses various interactive processes. One of alluring issues in this skill is relationship between phonological component and semantic representation. From this perspective, it is known that information of several sorts (phonetic, lexical, syntactic, and pragmatic) is processed during the comprehension process as the meaning is constructed (Bialystok, et al. 2003; Blaiklock, 2004; Byrne, 1991; Carroll \& Snowling, 2004; Coltheart et al. 1988; Harris and Coltheart, 1986). That said comprehension in reading, which is affected by both lower-level components and higher-level 
components, is a multifaceted set of processes, not an all-or-none operation. The line of evidence in favor of the effect of phonological component comes from several sources.

In this regard, most of the recent body of research hold the view that there is an interaction between the processing of the physical stimuli (bottom-up processing) and the context provided by expectation and previous knowledge (top-down processing) (Carrell et al., 1998). In line with this perspective, Koda (1992) indicates that lower level verbal processing skills (e.g., phonological processing) is one of the four major reader-related skills. He further adds that little attention has been paid to the relationship between lower level verbal processing skills and reading comprehension, but a number of theorists in cognitive psychology claim that deficiency in lower level processing operations strains the limited capacity of short-term memory and inhibits text integration into a meaningful sequence (e.g., Leong et al. 2005; Lesaux \& Siegel, 2003; Nation \& Snowling, 2004; Perfetti, 1986). Based on his findings, he holds that efficient lower level verbal processing operations are essential for successful performance in FL reading comprehension tasks.

More specifically, one of the lower level verbal processing mechanisms is phonological processing which is the task of linking printed letters to phonemes. This reading-specific processing is especially difficult for foreign language readers because of the lack of one-to-one correspondence between phonemes and graphemes.

In one study done by Deacon and Kirby (2004), the roles of morphological and phonological awareness on the reading development were taken into account. It was a longitudinal study which took 4 years. They compared two factors, namely phonological and morphological awareness, in three aspects of reading development: pseudoword reading, reading comprehension, and single word reading. The results of their study divulged that morphological awareness contributed significantly to pseudoword reading and reading comprehension, after controlling prior measures of reading ability, verbal and nonverbal intelligence, and phonological awareness. This contribution was comparable to that of phonological awareness and remained 3 years after morphological awareness was assessed. In contrast, morphological awareness rarely contributed significantly to single word reading. They argued that these results provided evidence that morphological awareness had a wide-ranging role in reading development, one that extended beyond phonological awareness.

Another study done by Nassaji and Geva (1999) investigated the role of phonological and orthographic processing skills in adult second language reading. The subjects were 60 ESL graduate students; all were native speakers of Farsi. Three types of ESL reading measures were used as criterion variables: reading comprehension, silent reading rate, and the ability to recognize individual words. Data were analyzed using correlational and hierarchical multiple regression. The analysis of the collected data revealed that efficiency in phonological and orthographic processing contributed significantly to individual differences on the reading measures. In particular, efficiency in orthographic processing contributed to the reading measures independently of syntactic and semantic measures. The study suggested that it was useful to consider individual differences in ESL reading with respect to individual differences in lower level processes - particularly the efficiency with which readers process phonological and orthographic information. This research (Nassaji and Geva, 1999) indicated that information about individual differences in the efficiency with which L2 readers process phonological and orthographic information helps us to understand individual differences in ESL reading. It suggested that the role of lower level graphophonic processing should not be overlooked in L2 reading, even when readers are proficient adult L2 readers.

Droop and Verhoeven (2003) gave much importance to the role of oral language proficiency in reading comprehension because the L2 reading comprehension skills are more dependent upon lexical knowledge than the L2 decoding skills. Bilingual Turkish-Dutch children, although comparable in word recognition, performed more poorly in reading comprehension than their monolingual Dutch-speaking peers. The authors attributed this lower level of comprehension to the lower performance in syntactic ability and oral fluency. Measures of Dutch oral language proficiency included both expressive and receptive vocabulary tasks, and an expressive syntactic task. However, both for native speakers and for L2 speakers, decoding skills played only a minor role in the development of reading comprehension, and according to the authors, decoding and reading comprehension appear to develop as independent skills from third grade on (Droop \& Verhoeven, 2003).

In agreement with these findings, studies have demonstrated a significant effect of oral language proficiency in L2 reading comprehension, although measures of L2 decoding predicting L2 reading comprehension were not analyzed. Geva and Ryan (1993) conducted a cross-sectional study with 73 students in Grades 5 to 7, who were learning to read in English (L1) and Hebrew (L2) concurrently. Regression analysis showed that Hebrew oral proficiency, as measured by teachers' global ratings, accounted for $29.8 \%$ of the variance on Hebrew reading comprehension scores. Corresponding with these results, Lindsey et al. (2003) reported that receptive vocabulary was one of the best predictors of English reading comprehension, but did not account for variance in decoding. Torgesen (2000), having 
devoted some investigation, summarized the importance of phonological awareness in acquiring accurate word reading skills. According to Torgesen (2000): First, phonological awareness helps children understand the alphabetic principle. Second, it helps children realize the regular ways that letters represent sounds in words. Lastly, it makes it possible to generate possibilities for words in context that are only partially sounded out.

Moreover, as Koda (2005) states, poor readers uniformly are handicapped in a wide variety of phonological tasks. Furthermore, Metsala \& Ehri (1998) state that comprehension is a meaning-construction process, which involves integral interaction between text and reader. Extracting phonological information from individual words constitutes one of the first and most important steps in this endeavor. Also phonological skills have a direct, and seemingly causal relationship with reading ability knowledge of letter patterns and their linkages to sounds facilitates rapid automatic word recognition; such knowledge evolves gradually through cumulative print-processing experience; and limited word-recognition skills tend to induce over reliance in context (p.254).

The central tenet of the mentioned studies is that links between phonological form and meaning can then produce meaning activation that is indirectly 'mediated' through phonology. One such model is the Interactive Constituency Theory (ICT) (Perfetti \& Tan, 1998; 1999 cited in Perfetti et al.2003). The ICT assumes that a phonological form is routinely activated as part of word identification because it is a constituent of the identified word. This phonological activation rapid and may precede the direct activation of specific word meaning in many situations. However, the ICT further assumes that phonological activation is diffuse across characters sharing the same pronunciation.

William and Lovatt (2003) have considered phonological awareness not only as a fundamental factor determining learner's reading ability but also as an important element helping vocabulary learning in both normal and language-impaired adults and children in L2 acquisition.

Snowling et al. (1991) have suggested that phonological awareness training perhaps should be incorporated into classroom activities to help young FL learners enhance word recall and pronunciation-learning ability or to ameliorate word-learning problems in FL.

Segalowitz et al. (1991) have also argued that the modification and specification of the word-referent relationship cannot proceed if the phonological pattern is obscure and incomplete. Thus, even though FL word learning is not a simple phonological issue, the establishment of a complete and solid phonological representation for a word still appears to be the first and the most important springboard to success in early FL vocabulary acquisition for a young FL learner.

Central to the relationship between phonological component and semantic component is the concept of automaticity which receives noticeable magnitude in 'bottom up' approaches to reading (Eskey, 1988; Torgesen, Wagner, Rashotte, Burgess, \& Hecht, 1997; William \& Lovatt, 2003)

Theoretically speaking, learning is viewed as a complex cognitive skill from the viewpoint of Cognitive Theory and Information Processing Models. Learning a skill, in McLaughlin's terms (1987), requires the automatization of component subskills. McLaughlin (1987) notes that one aspect of second language performance where the automatic/controlled processing distinction is especially relevant is reading. On the basis of researches reported by Shiffrin and Schneider (1977), Cziko (1980) and Segalowitz (1986, 2003), he adds that in learning to read, children utilize controlled processing as they move to more and more difficult levels of learning, the transition from controlled to automatic processing at each stage results in reduced discrimination time, more attention to higher order features and ignoring irrelevant information. Also, Smith (1981 cited in Bar-Shalom) refers to the same point when he claims that through practice the subcomponents, like phonological component, can be automatized, and controlled process would be freed for other functions.

More specifically, Perfetti et al. (1988, p. 59) suggest that automatic activation of phonetic properties of word during word identification routinely occurs in reading, while others believe that recoding of graphemic input into phonetic information does not occur. Their consensus answer seems to be that adult readers often use unmediated routes (visual route to semantic representation) (Byrne, 1991; Bar-Shalom et al., 1993).

From a pedagogical point of view, some researchers indicate that emphasizing perfect pronunciation can reduce comprehension (e.g., Rigg in Carrel et al., 1988; p. 215). Instead, others note that an awareness of the linguistic structure of words (both phonological and morphological) is virtually important to successful reading and spelling (e.g. Bar-Shalom et al., 1993; p. 197; Carlisle et al., 1993; p. 177-179; Cupples et al., 1992; p. 272).

Therefore, to sum it up, within the framework of cognitive theory, learning is a cognitive process which requires the integration of a number of different skills, each of which has been practiced and made routine (McLeod and McLaughlin, 1986; Segalowitz, 2003). According to McLauglin's (1987; p. 134), cognitive theory stresses the limited information processing capacities of human learners, the use of various techniques to overcome these 
limitations, and the role of practice in stretching resources so that component skills that require more mental work become routinized and thereby to free controlled process for other functions. He further continues that as automaticity develops, controlled search is bypassed and attentional limitations are overcome. The acquisition of a complex cognitive skill, such as learning a second language, is thought to involve the gradual accumulation of automatized subskills and a constant restructuring of internalized representations as the learner achieves increasing degrees of mastery.

In summary, consistent with many L1 studies and some recent L2 studies (e.g., Haynes \& Carr, 1990; Koda, 1992), the present research provides evidence for the utility of a multivariate information processing model in ESL reading. It suggests that L2 reading theories should take into account the role played by different component processes in L2 reading, including efficient phonological processing.

\section{Method}

\subsection{Participants}

The participants of the present study were 60 undergraduate ESP students selected out of 130 ESP students volunteering to participate in this study. In fact, these 60 students were screened based on their scores on reading section of a TOEFL and were regarded as of nearly the same proficiency level. The participants included both male and female students. Their age range varied from 18 to 25 .

\subsection{Instruments}

2.2.1 The Pre-test: A test comprising of the reading comprehension parts of a TOEFL test which included 50 multiple-choice items. This TOEFL test had, in fact, two purposes: a) to homogenize the students and b) to specify the learner's ability in comprehending texts before going through the procedures of this study.

2.2.2 The Post-test: To see whether the automatization of phonological component would have any significant effect on ESP student's reading comprehension improvement, another 50- TOEFL actual test (only reading section) was conducted.

\subsection{Procedure}

The participants were randomly assigned to two groups of control and experimental. The approach employed in the control group was the traditional approach of teaching reading which was based on literal translation of the texts and answering some reading comprehension questions with no emphasis on pronunciation. While in the experimental group the researcher used different techniques to improve pronunciation. The treatment phase which lasted for a period of a semester involved practice on pronunciation. More specifically, it involved: a) awareness of phonological form of letters, clusters of letters, and words in hierarchical stages of identification, repetition, discrimination, and production b) transcription of words, phrases, sentences into the phonetic alphabet and transcription of the phonetic forms of words, phrases, sentences into conventional alphabets c) practice on reading phrase-by-phrase, clause-by-clause, and sentence-by-sentence; practice on oral timed reading without reference to meaning.

\subsection{Statistical Analysis}

In order to answer the research question, the mean scores of the control and experimental groups were compared using an independent samples T-test. This was done to see if there was any significant difference between the performance of the control and experimental group on the post-test.

\section{Results}

In order to analyze the gathered data, first the mean scores of experimental and control groups in pretest were compared with each other, second the mean scores of experimental and control groups in posttest were compared with each other.

With regard to the statistical data presented in table 1, a mean score of 34.73 with a standard deviation of 9.74 was obtained for the control group, while the mean score of 34.93 with a standard deviation of 10.31 was gained for the experimental group on the pre-test. Therefore, it can be concluded that the two groups were homogeneous in terms of their reading comprehension. Also as shown in the table 1, we find out that the t-critical value is higher than our t-observed 0.077 at 0.05 level of significance, i.e. $t(58)=0.077$. The Sig (2-tailed) 0.93 is higher than the assumed level of significance 0.05 , this indicates that there was not any statistically significant difference between control and experimental group prior to the initiation of the treatment of the study. 
Table 1 also indicates that there has been a significant gain in the mean score of experimental group after the treatment. A mean score of 35.7 with a standard deviation of 10.7 was obtained for the control group, while the mean score of 42.3 with a standard deviation of 13.3 was gained for the experimental group on the post-test.

Also as far as the results of the results of the independent samples T-test is concerned, with 58 degrees of freedom our t-observed at 0.05 level of significance, i.e., $\mathrm{t}(58)=2.11$, exceeds the $\mathrm{t}$-critical value and means that the observed difference between groups is meaningful. The Sig (2-tailed) 0.039 is also evidence which is smaller than the assumed level of significance 0.05 , therefore, it can be concluded that the automatization of phonological component as a new approach to reading instruction is significantly better than the traditional approach in reading instruction. Therefore, the treatment has enhanced the reading comprehension ability of the experimental group on the post-test.

\section{Conclusion and Discussion}

The statistical analyses revealed that teaching reading comprehension through pronunciation practice (i.e. automatization of phonological component) did have a significant effect on the ESP students' reading comprehension. Therefore, it can be said that ESP students benefited from pronunciation practice and phonological awareness in reading instruction more than the traditional approach of reading instruction. Since the very nature of reading processing mechanism is a not easily investigated, the reading research domain doesn't not seem to be a promising or inviting one; nevertheless, it is a field that has attracted many researchers, partly due to its very intricacy, and partly because any finding and discovery concerning the reading process would have immediate applications and implications for L2 language learning.

The present study was designed to shed some light on the role of phonological processing as one of the bottom-up processing mechanism on the more efficiency of top-down processing such as comprehension. In agreement with this line of research in L2 reading and with the obtained, empirical results of the studies done recently, it can be argued that the abstract models of reading process in which the role of bottom-up, component processes are systematically neglected, have a little contribution to make. Such models of reading, are in general, models of the ideal fluent reader with completely developed knowledge systems and skills, whereas the foreign language reader is, almost by definition, a developing reader with gaps and limitations.

These results of the recent studies, including this study, in which lower-level processes and their routinization and automaticity have proved to enhance reading comprehension, weaken considerably the common assumption in L2 that the availability of higher level processes in reading comprehension reduces significantly the contribution of lower level processes (Nassaji \& Geva, 1999). Such studies also challenge the idea articulated by researchers such as Coady (1979) that, as L2 readers become more proficient (i.e., as they increase their command of L2 vocabulary, syntax, and discourse markers), they move away from using lower level skills and instead rely on higher level semantic and syntactic skills (Nassaji \& Geva, 1999).

As far as cognitive theory is concerned, the present study tried to show that the automatization of phonological component in foreign language environment is a useful information-processing technique to overcome capacity limitation and mind's limited capacity, which can free controlled process for other functions such as comprehension. In this way, this research contributes to foreign language learning on the basis of empirical findings in foreign language classroom to determine cognitive theory's worth.

This study may also have implications for language teaching and syllabus design. From a practical point of view, a fuller appreciation of the central process of automatization has important implications for foreign language teaching. On the basis of findings, it is suggested that some time must be devoted in reading classes to development of relatively bottom-up concerns such as practice on pronunciation. Even students who have developed top-down skills in their native languages may not be able to transfer higher level skills to a second language context until they have developed a stronger bottom-up foundation of basic identification skills through translation of letters to sounds.

\section{References}

Bar-Shalom, E.G., Crain, S., \& Shankweiler, D. (1993). A comparison of comprehension and production abilities of good and poor readers. Applied Psycholinguistics, 14, 127-227. http://dx.doi.org/10.1017/S0142716400009553

Bialystok, E., Majumder, S., \& Martin, M. M. (2003). Developing phonological awareness: Is there a bilingual advantage? Applied Psycholinguistics, 24(1), 27-44. http://dx.doi.org/10.1017/S014271640300002X

Blaiklock, K. E. (2004). The importance of letter knowledge in the relationship between phonological awareness and reading. Journal of Research in Reading, 27(1), 36-57. http://dx.doi.org/10.1111/j.1467-9817.2004.00213.x 
Byrne, B. (1991). The role of phonological awareness in reading acquisition. Australian Journal of Reading, 14(2), 133-139

Carlisle, J. F., \& Nomanbhoy, D. M. (1993). Phonological and morphological awareness in first graders. Applied Psycholinguistics, 14: 177-195. http://dx.doi.org/10.1017/S0142716400009541

Carrell, P., Devine, Y., \& Eskey, D. (1988). Interactive Approaches to second language reading. Cambridge: Cambridge University Press.

Carroll, J. M., \& Snowling, M. J. (2004). Language and phonological skills in children at high risk of reading difficulties. The Journal of Child Psychology and Psychiatry and Allied Disciplines, 45(3), 631-640. http://dx.doi.org/10.1111/j.1469-7610.2004.00252.x

Coady, J. (1979). A psycholinguistic model of the ESL reader. In R. Mackay, B. Barkman, \& R. R. Jordan (Eds.), Reading in a second language (pp. 5-12). Rowley, MA: Newbury.

Coltheart, V., Laxon, V., Richard, M., \& Elton, C. (1988). Phonological recoding in reading for meaning by adults and children. Journal of Experimental Psychology: Learning, Memory, and Cognition, 14, 387-397. http://dx.doi.org/10.1037/0278-7393.14.3.387

Cupples, L., \& Holmes, V. M. (1992). Evidence for a Difference in Syntactic Knowledge between Skilled and Less Skilled Adult Readers. Journal of Psycholinguistic Research, 21: 249-273. http://dx.doi.org/10.1007/BF01067513

Cziko, G. A. (1978). Differences in first- and second-language reading: The use of syntactic, semantic and discourse constraints. Canadian Modern Language Review, 34, 473-489

(1980). Language competence and reading strategies: A comparison of first and second language oral reading errors. Language Learning, 30, 101-114. http://dx.doi.org/10.1111/j.1467-1770.1980.tb00153.x

Deacon, S. H., \& Kirby, J. R. (2004). Morphological awareness: Just "more phonological"? The roles of morphological and phonological awareness in reading development. Applied Psycholinguistics 25 (2004), 223-238

Droop, M., \& Verhoeven, L. (2003). Language proficiency and reading ability in first and second language learners. Reading Research Quarterly, 38, 78-103. Quoted in Grabe William (2004). Research on teaching reading. Annual Review of Applied Linguistics, 24, 44-69

Eskey, D. (1988). Holding in the bottom: An interactive approach to the problem of sound language readers .In (Carrell, P. L., Devine, J. \& Esky, D. E. Eds.), Interactive approaches to second language learning. (pp.130-152). New York: Cambridge University Press.

Geva, E., \& Ryan, E. B. (1993). Linguistic and cognitive correlates of academic skills in first and second languages. Language Learning, 43, 5-42. http://dx.doi.org/10.1111/j.1467-1770.1993.tb00171.x

Harris, M., \& Coltheart, M. (1986). Language Processing in Children and Adults: An Introduction. London: Rutledge and Kegan Paul.

Hasher, L., \& Zacks, R.T. (1979). Automatic and Effortful Processes in Memory. Journal of Experimental Psychology: General, 108:356-388. http://dx.doi.org/10.1037/0096-3445.108.3.356

Haynes, M., \& Carr, T. (1990). Writing system background and second language reading: A component skills analysis of English reading by native speakers of Chinese. In T. Carr \& B. Levy (Eds.), Reading and its development: Component skills approaches (pp. 375-421). San Diego: Academic.

Koda, K. (2005). Insights into second language reading: a cross-linguistic approach. Cambridge, UK: New York, NY: Cambridge University Press.

Koda, K. (1992). The effect of lower-level processing skills on FL reading performance: Implications for instruction. The Modern Language Journal, 76, 505-512. http://dx.doi.org/10.2307/330051

Leong, C. K., Hau, K. T., Cheng, P. W., \& Tan, L. H. (2005). Exploring two-wave Reciprocal Structural Relations among Orthographic Knowledge, Phonological Sensitivity, Reading and Spelling English Words by Chinese Students, Journal of Educational Psychology, Vol. 97, 591-600. http://dx.doi.org/10.1037/0022-0663.97.4.591

Lesaux, N. K., \& Siegel, L. S. (2003). The Development of Reading in Children Who Speak English as a Second Language. Developmental Psychology, 39, 6, 1005-1019. http://dx.doi.org/10.1037/0012-1649.39.6.1005

McLaughlin, B. (1987). Theories of second language learning. New York: Edward Arnold.

McLeod, B., \& McLaughlin, B. (1986). Restructuring or automatization? Reading in a second language. Language Learning, 36, 109-127. http://dx.doi.org/10.1111/j.1467-1770.1986.tb00374.x 
Metsala, J. L., \& Ehri, L. C. (1998). Word recognition in beginning literacy (pp.3-40)[electronic resource]. Mahwah, N.J.: L. Erlbaum Associates.

Nassaji, H., \& Geva, E. (1999). The contribution of phonological and orthographic processing skills to adult ESL reading: Evidence from native speakers of Farsi. Applied Psycholinguistics, 20, 241-267. http://dx.doi.org/10.1017/S0142716499002040

Nation, K., \& Snowling, M. J. (2004). Beyond phonological skills: Broader language skills contribute to the development of reading. Journal of Research in Reading, 27(4), 342-356. http://dx.doi.org/10.1111/j.1467-9817.2004.00238.x

Perfetti, C. A., Bell, L. C., \& Delaney, S. M. (1988). Automatic (Pre-lexical) Phonetic Activation in Silent Word Reading: Evidence from Backward Masking. Journal of Memory and Language, 27: 59-70. http://dx.doi.org/10.1016/0749-596X(88)90048-4

Perfetti, C. A., Koda, K., \& Wang, M. (2003). Alphabetic and nonalphabetic L1 effects in English word identification: a comparison of Korean and Chinese English L2 learners. Cognition, 87(2), 129-149. http://dx.doi.org/10.1016/s0010-0277(02)00232-9

Segalowitz, N. (2003). Automaticity and second languages. In C. Doughty and M. H. Long (Eds.), The Handbook of Second Language Acquisition, 382-408. http://dx.doi.org/10.1002/9780470756492.ch13

Segalowitz, N., Poulsen, C., \& Komoda, M. (1991). Lower-level components of reading skill in higher level bilinguals: Implications for reading instruction. AILA Review, 8, 15-3. Malden, MA: Blackwell.

Shiffrin, R. M., \& Schneider, W. (1977). Controlled and Automatic Human Information Processing. II: Perceptual Learning, Automatic, Attending and a General Theory. Psychological Review, 84: 127-190. http://dx.doi.org/10.1037/0033-295X.84.2.127

Snowling, M., Chiat, S., \& Hulme, C. (1991). Words, nonwords, and phonological processes: Some comments on Gathercole, Willi, Emslie and Baddeley. Applied Psycholingustics, 12, 369-73. http://dx.doi.org/10.1017/S0142716400009279

Torgesen, J. K. (2000). A basic guide to understanding, assessing, and teaching phonological awareness. Austin, Tex.: Pro-Ed Mass.

Torgesen, J. K., Wagner, R. K., Rashotte, C. A., Burgess, S., \& Hecht, S. (1997). Contributions of phonological awareness and rapid automatic naming ability to the growth of word-reading skills in second- to fifth-grade children. Scientific Studies of Reading, 1(2), 161-185. http://dx.doi.org/10.1207/s1532799xssr0102_4

William, J. N., \& Lovatt, P. (2003). Phonological memory and rule learning. Language Learning Journal. 53, (1), 67-121. http://dx.doi.org/10.1111/1467-9922.00211

Table 1. Comparing differences between two groups

\begin{tabular}{lcccccc}
\hline & Group & $\mathbf{N}$ & Mean & Std. Deviation & t* & Sig \\
\hline \multirow{3}{*}{ Pre-test } & experiment & 30 & 34.93 & 10.31 & & \\
& control & 30 & 34.73 & 9.74 & 0.077 & 0.93 \\
& Experiment & 30 & 42.33 & 13.35 & 2.11 & 0.039 \\
Post-test & control & 30 & 35.73 & 10.72 & & \\
\hline
\end{tabular}

$* P<0.05$ 